\title{
Consent for Treatment in the UK - 2017 Update
}

Paul Y F Lee ${ }^{1,2}$, Amelia Davies ${ }^{1}$, Bethan Whiting ${ }^{2}$ and Saqib Masud ${ }^{1{ }^{*}}$

${ }^{1}$ Welshbone, South Wales Orthopaedics Research Network, Wales, UK

${ }^{2}$ LEO Institute, Grantham and District Hospital, Grantham, Lincolnshire

*Corresponding author: Saqib Masud, Welshbone, South Wales Orthopaedics Research Network, Wales, UK, Tel: +447764614688; E-mail: saqib_masud@hotmail.com

\section{Received date: July 17, 2017; Accepted date: July 18, 2017; Published date: June 20, 2017}

Copyright: (c) 2017 Lee PYF, et al. This is an open-access article distributed under the terms of the Creative Commons Attribution License, which permits unrestricted use, distribution, and reproduction in any medium, provided the original author and source are credited.

\section{Editorial}

There are many options in the treatment of arthritis, whether it is a medical or surgical treatment, doctors must obtain consent from their patients. Without valid consent, any form of treatment can be viewed as assault and will have legal implications.

Catering for all educational levels, ethnicities and ages with medical consent has always been difficult. There is a general consensus in the literature that there is a need for a review of treatment consent to ensure patient comprehension and satisfaction. In recent years, the medical profession has found an increase in the cost of litigation. Marino et al. [1] highlighted that in Italy Trauma and Orthopaedics is the "most sued" specialty and Kadakia et al. [2] showed that patients actually have very little understanding when questioned about their own trauma. The study found that less than half of the patients knew what bone they had fractured and less than $20 \%$ knew their recovery time. This suggests the need for a reform in how patients are given information to ensure higher comprehension and satisfaction in surgical procedures. The General Medical Council [3], in "Good Medical Practice" 2013, detailed that exchange of information is key to good decision making and so how are patients expected to make informed decisions when they do not know the information? A recent supreme court judgement has altered the legal landscape in the consent process in the UK. The outcome of the Montgomery $\mathrm{v}$ Lanarkshire Health Board legal battle has become a landmark Scottish case and has had a profound effect on the British legal system as the judgment disseminated from the highest British court.

Comprehension, satisfaction and anxiety are the three key aspects that medical consent needs to address. Consent has traditionally been given verbally by the surgeon. However, Goldberger et al. [4] showed that oral consent by a physician requires more time than written or video consent to produce the same level of comprehension. In an over stretched NHS, time saving procedures such as this could reduce pressures on physician time without affecting the patient's comprehension and sense of satisfaction.

Both Ashraff et al. and Langdon et al. [5,6] showed that leaflets increase patient comprehension by increasing patients' ability to recall by more than $25 \%$ and so are useful tools for surgeons to improve informed consent. However, Terranova, et al. [7] found using FleschKincaid grade level text analysis that consent forms were too confusing and complicated for patients to comprehend. This highlights that if leaflets are to be given they need to be reviewed and improved for greater patient understanding. It is important to provide sufficient information as Sato et al. [8] showed that satisfaction is increased with the amount of information given. However, this was a group of people with higher education and so giving large amounts of information to people with lower literacy levels may increase anxiety. This emphasizes the importance of leaflets being clear for patients containing both writing and graphics to cater to all educational levels.

In an age when people are becoming more computer literate, Fraval et al. [9] showed that web based educational tools increase patient comprehension and satisfaction before an elective procedure without increasing anxiety levels. Corniou A et al. [10] also showed that patients have greater comprehension and satisfaction when using computer-based multimedia compared with pamphlets and standard verbal consent. This suggests that computer programs could be used more to aid informed consent, especially among the younger generation. However, this may not be beneficial for the older population who are known to be less likely to use information and communications technology or for those who do not have access to a computer.

The need to cater for all when informing patients of surgical procedures is very challenging. The literature reveals that reform is needed to modernize the consent methods that are traditionally used. A user friendly multimedia online platform across multiple devices may be the best way forward to improve and engage patients in the consent process.

Zickuhr et al. [11] showed that in the USA the percentage of older people going online is increasing. This indicates that in a few years a large majority of the population will be able to use and have access to a computer, tablet or smart phone. Apps and other computer programs are being used increasingly in medicine and providing information in an interactive format engages patients more. A multimedia consent program such as consentplus.com could be a good way to increase patient comprehension and satisfaction without increasing anxiety.

A friendly multimedia online platform allows patients to take their time looking through the information at home and then they can discuss it with health professionals during clinic appointments. An innovative solution, consentplus.com, could be the way forward to maximize engagement and for a patient to give informed consent. Further research is needed in this area.

\section{References}

1. Marino V, Marsella LT, Eramo A, Tarantino U, Via AG (2011) Professional liability in orthopaedics and traumatology. Rechtsmedizin 21: 0937-9819.

2. Kadakia RJ, Tsahakis JM, Issar NM, Archer KR, Jahangir AA (2013) Health literacy in an orthopedic trauma patient population: a cross-sectional survey of patient comprehension. J Orthop Trauma 27: 467-471.

3. General Medical Council (2013) Consent: patients and doctors making decisions together.

4. Goldberger JJ, Kruse J, Kadish AH, Passman R, Bergner DW (2011) Effect of informed consent format on patient anxiety, knowledge, and satisfaction. Am Heart J 162: 780-785. 
Citation: Lee PYF, Davies A, Whiting B, Masud S (2017) Consent for Treatment in the UK - 2017 Update. J Arthritis 6: e116. doi:

Page 2 of 2

5. Ashraff S, Malawa G, Dolan T, Khanduja V (2006) Prospective randomised controlled trial on the role of patient information leaflets in obtaining informed consent. ANZ J Surg 76: 139-141.

6. Langdon IJ, Hardin R, Learmonth ID (2002) Informed consent for total hip arthroplasty: does a written information sheet improve recall by patients? Ann R Coll Surg Engl 84: 404-408.

7. Terranova G, Ferro M, Carpeggiani C, Recchia V, Braga L (2012) Low quality and lack of clarity of current informed consent forms in cardiology: how to improve them. JACC Cardiovasc Imaging 5: 649-655.

8. Sato K, Watanabe T, Katsumata N, Sato T, Ohashi Y (2014) Satisfying the needs of Japanese cancer patients: a comparative study of detailed and standard informed consent documents. Clin Trials 11: 86-95.
9. Fraval A, Chandrananth J, Chong YM, Coventry LS, Tran P (2015) Internet based patient education improves informed consent for elective orthopaedic surgery: A randomized controlled trial. BMC Musculoskelet Disord 16: 1471-2474.

10. Cornoiu A, Beischer AD, Donnan L, Graves S, Steiger R (2011) Multimedia patient education to assist the informed consent process for knee arthroscopy. ANZ J Surg 81: 176-180.

11. Zickuhr K, Madden M (2012) Older adults and internet use. Pew Research Centre's Internet \& American Life Project. 